\title{
A multi-nutrient supplement reduced markers of inflammation and improved physical performance in active individuals of middle to older age: a randomized, double-blind, placebo-controlled study
}

Courtenay Dunn-Lewis, William J Kraemer*, Brian R Kupchak, Neil A Kelly, Brent A Creighton, Hui-Ying Luk, Kevin D Ballard, Brett A Comstock, Tunde K Szivak, David R Hooper, Craig R Denegar and Jeff S Volek

\begin{abstract}
Background: While exercise acts to combat inflammation and aging, the ability to exercise may itself be compromised by inflammation and inflammation's impact on muscle recovery and joint inflammation. A number of nutritional supplements have been shown to reduce inflammation and improve recovery. The purpose of the current investigation was to examine the effect of a multi-nutrient supplement containing branched chain amino acids, taurine, anti-inflammatory plant extracts, and B vitamins on inflammatory status, endothelial function, physical function, and mood in middle-aged individuals.
\end{abstract}

Methods: Thirty-one healthy and active men ( $N=16$, mean age $56 \pm 6.0 \mathrm{yrs})$ and women $(N=15$, mean age $=$ $52 \pm 7.5 \mathrm{yrs}$ ) participated in this investigation. Subjects completed one 28 day cycle of placebo supplementation and one 28 day cycle of multi-nutrient supplementation (separated by a one week washout period) in a balanced, randomized, double-blind, cross-over design. Subjects completed weekly perceptual logs (PROMIS-57, KOOS) and pre- and post- testing around the supplementation period. Testing consisted of brachial artery flow mediated dilation (FMD), blood measures, and physical performance on vertical jump, handgrip strength, and balance (dispersion from center of pressure). Significance for the investigation was $p \leq 0.05$.

Results: IL-6 significantly decreased in both men (from $1.2 \pm 0.2$ to $0.7 \pm 0.4 \mathrm{pg} \cdot \mathrm{mL}^{-1}$ ) and women (from $1.16 \pm$ 0.04 to $0.7 \pm 0.4 \mathrm{pg} \cdot \mathrm{mL}^{-1}$ ). Perceived energy also improved for both men (placebo: $1.8 \pm 0.7$; supplement: $3.7 \pm 0.8$ AUC) and women (placebo: $1.2 \pm 0.7$; supplement: $2.8 \pm 0.8$ AUC). Alpha-1-antichymotrypsin (from $108.9 \pm 38.6$ to $55.5 \pm 22.2 \mathrm{ug} \cdot \mathrm{mL}^{-1}$ ), Creatine Kinase (from $96 \pm 34$ to $67 \pm 23 \mathrm{IU} \cdot \mathrm{L}^{-1}$ ), general pain, and joint pain decreased in men only, while anxiety and balance (from $0.52 \pm 0.13$ to $0.45 \pm 0.12 \mathrm{~cm}$ ) improved in women only. Men showed increased performance in vertical jump power (from $2642 \pm 244$ to $3134 \pm 282 \mathrm{~W}$ ) and grip strength (from $42.1 \pm$ 5.9 to $48.5 \pm 4.9 \mathrm{~kg}$ ).

Conclusions: A multi-nutrient supplement is effective in improving inflammatory status in both men and women, markers of pain, joint pain, strength, and power in men only, and both anxiety and balance (a risk factor for hip fracture) in women. Therefore, a multi-nutrient supplement may help middle-aged individuals to prolong physical function and maintain a healthy, active lifestyle.

Keywords: Aging, Supplementation, Resistance Exercise, Amino Acids, Joint, Recovery, Vitamin B

\footnotetext{
* Correspondence: william.kraemer@uconn.edu

Human Performance Laboratory, Department of Kinesiology, University of Connecticut, Storrs, CT, 06269, USA
} 


\section{Background}

Aging has long been portrayed as an unpredictable, indiscriminate process of degeneration in cognitive and physical function. This harsh view has been challenged by our modern understanding of the role that agerelated increases in inflammation play in chronic disease and aging [1]. It now appears that physiological wellbeing at advanced age may be influenced by the everyday anti-inflammatory habits of the individual [2]. Simple lifestyle choices, such as physical exercise and dietary patterns, may address chronic systemic inflammation and improve long-term health and function $[3,4]$. We now appreciate that inflammatory cytokines may be influenced by habitual behavior; this includes Interleukin-6 (IL-6), an inflammatory cytokine strongly associated with cognitive impairment [5], functional decline, loss of strength, sarcopenia, and mortality [6]. Indeed, exercise and nutrition may attenuate even the processes of aging that were once considered inevitable, such as declines in cognitive function, mood, sarcopenia, quality of life [7]. Our modern concept therefore suggests that although the processes of aging and inflammation certainly cannot be halted, it may be possible to extend cognitive and physical function long-term through appropriate diet and exercise practices.

While exercise acts as an important anti-inflammatory aid, the ability to recover from exercise in and of itself may be subject to the challenges of age-related inflammation. Aging is accompanied by increased free radical formation and circulatory changes that exacerbate inflammatory processes. This inflammatory cascade may include an increase in IL-6 - ordinarily an important component of muscle hypertrophy, but an inhibitor of muscle recovery at elevated concentrations [8]. IL-6 promotes chronic inflammation [9] and plays a large role in joint inflammation $[10,11]$. IL-6 contributes to the production of ACT [12] and together, the two inflammatory markers are associated with a two- to three-fold risk of reduced muscle strength in older adults [13]. At the same time, upstream hormonal signal processes, which are vital in gene expression and protein synthesis for both contractile and non-contractile proteins in skeletal muscle, also decline with age. The recovery of muscle and tissue slows with age, repair and remodeling of muscle is compromised, and inflammatory joint pain may persist (even in the absence of rheumatoid arthritis). Osteoporosis becomes a increasing concern, particularly in women; with age, the incidence of falling and the severity of fall-related injury increases dramatically, resulting in increased nursing home admissions [14] and hip fractures that significantly increase risk of mortality [15]. Furthermore, vascular endothelial dysfunction (as demonstrated by reduced brachial artery flow mediated dilation (FMD)) has been reported in healthy, sedentary middle-aged and older adults $[16,17]$, and is regarded as an early manifestation of CVD [18]. Brachial artery FMD is inversely related to plasma markers of inflammation [19] and inflammation-induced oxidative stress potentially mediates endothelial dysfunction [20] in middle-aged and older adults (thus interventions that improve endothelial homeostasis may have important clinical implications to reduce CVD-related morbidity and mortality). Combined, these factors result in progressive functional limitations and disability. As such, while exercise is an important factor in fighting inflammation, aging individuals may need additional nutritional support to combat the effect of inflammation on the body, improve recovery from and adaptation to exercise, and therefore permit them to remain physically active with age.

Given the importance of chronic inflammation and recovery to health, a number of studies have found that certain nutritional supplements, in combination with a healthy, balanced diet and exercise, may allow for improved recovery and anti-inflammatory action [21]. Branched chain amino acids (BCAA), for example, have analgesic properties [22] and may inhibit the breakdown of muscle protein and enhance muscle protein synthesis [23]; this has been particularly shown with leucine supplementation [24]. Taurine, also amino acid, acts as a powerful anti-inflammatory that may reduce IL- 6 production [25]. Green tea, a source of polyphenols, has chelating [26], anti-inflammatory, antibacterial, antimutagenic, anti-diabetic, and hypocholesterolemic properties [27]. It may help in cancer prevention, weight loss or management, stroke prevention, and prevention of cardiovascular disease [28]. Quercetin, another antiinflammatory aid [29], may inhibit mast cell activation [30], serve as a psychostimulant, and improve physiological performance, health, and disease resistance [31]. Cat's claw or uncaria tomentosa, a wood-like vine, is another powerful antioxidant and anti-inflammatory [32]. In a separate role, B-vitamins have limited antiinflammatory properties but are cofactors, crucial in metabolism, may increase energy (especially if diet is poor), and may improve mood and stress $[33,34]$. Therefore, a number of substances exist that improve agerelated recovery and inflammation in distinct and independent ways.

While each of the nutritional substances noted impart powerful physiological effects, each act independently and individually lacks the benefits that others may possess. Thus, the multifaceted impact of inflammation and aging on exercise performance may benefit from a multidimensional supplement that includes each of these substances in a single supplement. Although the ingredients independently have been shown to contribute to amino acid signaling, reduction of inflammation, and 
recovery, it is not currently known if a combined supplement would benefit recovery, joint health, remodeling of muscle, and energy in healthy individuals attempting to remain physically active. Therefore, the purpose of this study is to examine the effects of a multi-nutrient supplement on physical performance, endothelial function, fatigue, mood, and other recovery factors in active men and women from the ages 40-70 years.

\section{Methods}

\section{Experimental Design}

This investigation utilized a balanced, cross-over, withingroup, placebo-controlled design to examine the effects of the multi-nutrient supplement (BioCharge ${ }^{\mathbb{R}}$, Advocare, Plano, TX; please see Table 1 for ingredients) on physical performance, joint health, fatigue, mood, and inflammation during the recovery period of active subjects. (The placebo included the same natural raspberry flavor, sucralose, and natural beet-derived color that matched the natural form and color of the active supplement). As seen in Figure 1, the study consisted of two cycles (one cycle of BioCharge ${ }^{\circledR}$, one of placebo, the order randomly assigned in a balanced fashion). The funding agency blinded the supplement and placebo (as $A$ and $B$ ). No indication of this assignment was provided (either on the packaging or otherwise) to any member of the study staff or any subject until after data collection and analysis had ceased. Each cycle required four weeks (28 days) of supplementation between its first and last visit at which time subjects mixed one packet of the powdered supplement or an identical but otherwise inactive placebo each day with 4-8 ounces of water. Between the two cycles there was a washout period of at least one week and subjects were asked to maintain the same level of activity between both cycles (as verified by activity questionnaire). The four testing visits occurred immediately before and immediately following the supplementation period. Testing consisted of assessment of endothelial function via high-resolution ultrasonography, blood draws, and physical tests (handgrip, quiet standing, and vertical jumps). In addition, at the end of each week of each supplementation cycle, subjects filled out a logbook at home. Registered dieticians ensured compliance to supplement protocol and daily consumption.

\section{Subjects}

Thirty-one healthy and recreationally active subjects participated in this investigation (16 men and 15 women). Subject characteristics were (Mean \pm SD), men $(\mathrm{n}=16)$ : age, $56.0 \pm 6.0$ yrs, height, $177.3 \pm 3.8 \mathrm{~cm}$, body mass, $85.3 \pm 8.9 \mathrm{~kg}$; women $(\mathrm{n}=15)$ : age, $52.0 \pm$ 7.5 yrs, height, $168.4 .3 \pm 4.2 \mathrm{~cm}$, body mass, $75.5 \pm 10.7$ $\mathrm{kg}$. Subjects were recreationally active (expending

Table 1 Ingredients of Biocharge ${ }^{\circledR}$ supplement

\begin{tabular}{|c|c|c|}
\hline \multicolumn{3}{|l|}{$\begin{array}{l}\text { Supplement Facts } \\
\text { Serving Size: } 1 \text { packet added to water } \\
\text { Servings Per Container: } 14 \text { packets per carton }\end{array}$} \\
\hline & $\begin{array}{l}\text { Amt Per } \\
\text { Serving }\end{array}$ & $\% D V$ \\
\hline \multicolumn{3}{|l|}{ B Vitamins } \\
\hline Vitamin B12 & $0.25 \mathrm{mg}$ & $4200 \%$ \\
\hline Vitamin B6 & $6 \mathrm{mg}$ & $300 \%$ \\
\hline Folic acid (Vitamin B9) & $0.40 \mathrm{mg}$ & $100 \%$ \\
\hline Pantothenic Acid (Vitamin B5) & $20 \mathrm{mg}$ & $200 \%$ \\
\hline \multicolumn{3}{|l|}{ Amino Acids } \\
\hline Taurine & $500 \mathrm{mg}$ & * \\
\hline 1-Leucine & $2000 \mathrm{mg}$ & * \\
\hline Isoleucine & $500 \mathrm{mg}$ & * \\
\hline Valine & $500 \mathrm{mg}$ & * \\
\hline \multicolumn{3}{|l|}{ Plant Extracts } \\
\hline Cat's Claw (uncaria tomentosa) & 100 mg & ${ }^{*}$ \\
\hline Quercitin & 100 mg & * \\
\hline Green tea & $50 \mathrm{mg}$ & * \\
\hline $\begin{array}{l}\text { Biovin grape extract (full spectrum whole grape extract). } \\
\text { Contains Proanthocyanidins (OPC), Polyphenols, and Trans-resverattrol }\end{array}$ & $25 \mathrm{mg}$ & * \\
\hline *Daily Value (DV) not established & & \\
\hline
\end{tabular}




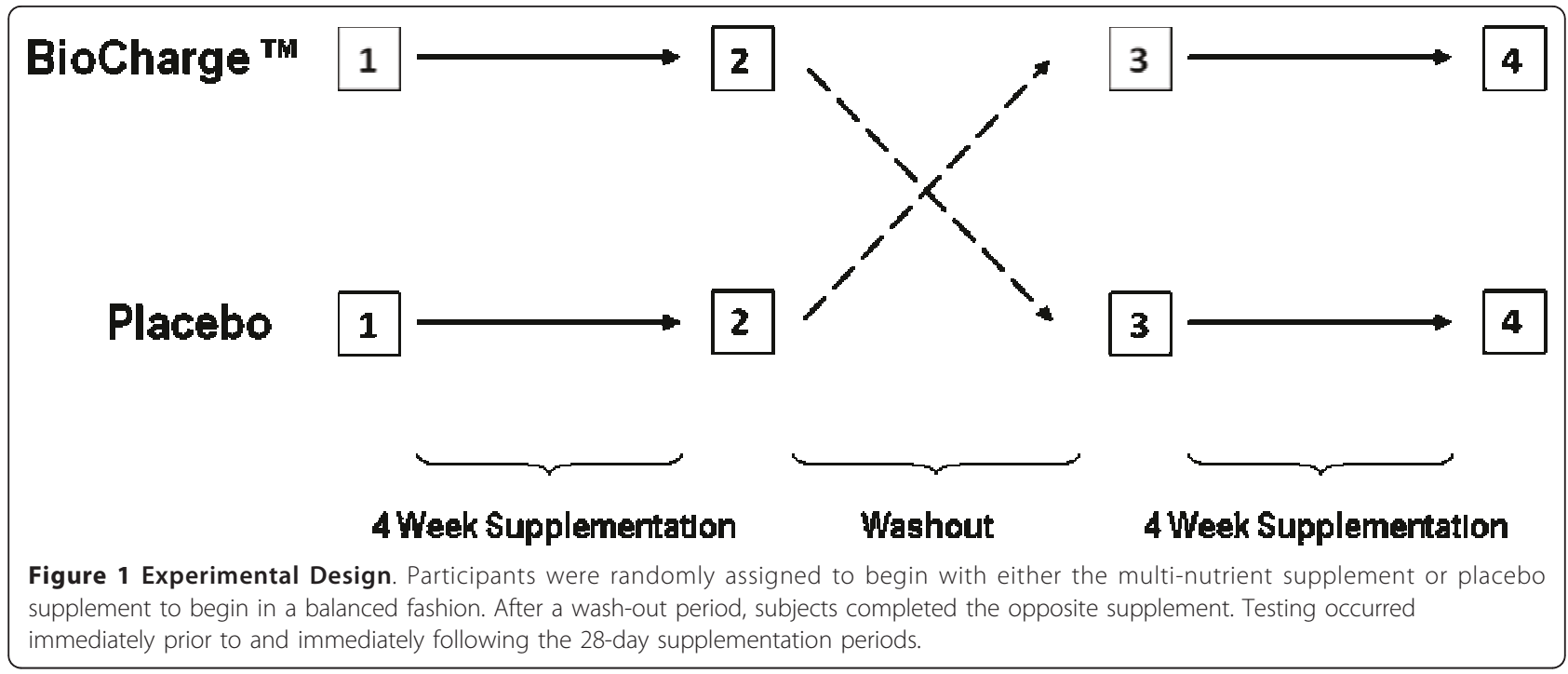

approximately 750 to 24,000 METS weekly, with vigorous activity accounting for approximately $2080 \pm 2300$ METS per week) and participated in various activities (none were trained master athletes).

Our medical monitor screened subjects for pre-existing medical conditions that could put subjects at risk or interfere with the investigation. Exclusion criteria included, but were not limited to: heart conditions or anomalies; respiratory conditions; blood pressure problems; and musculoskeletal problems or previous orthopedic injuries that would limit the range of motion. In addition, participants were excluded if they had recently taken or planned to take any products containing creatine, ephedra, and high doses of caffeine. All subjects were fully informed of the protocol design and associated risks of this investigation before signing an informed consent approved by the University of Connecticut Institutional Review Board for use of human subjects.

\section{Procedures}

Treatment conditions Subjects were asked to continue their normal workouts during the study and maintain the same level of activity between both cycles. To ensure consistency of their daily activities during the two supplementation periods, subjects were asked to fill out the logbook which included a physical activity report and a medication treatment log for the end of each week. Subjects were asked to fast (other than water as subjects were instructed on hydration protocols with urine specific gravity used for verification) for 12 hours prior to the lab visit. Exercise was not permitted 24 hours prior to visits and all visits occurred in the morning and within a one-hour window of their first visit.

Flow Mediated Dilation Endothelium-dependent FMD was assessed non-invasively in the peripheral circulation using high-frequency ultrasonographic imaging (Acuson Corp, Elmwood) Park, NJ) at each testing visit as described [35] with minor modification. Briefly, brachial artery FMD was measured following a 5 min occlusion of the forearm as this method is suggested to better reflect nitric oxide $\left(\mathrm{NO}^{\circ}\right)$-mediated vascular dilation compared to upper arm occlusion [36]. All vascular measurements and analysis were performed by two trained investigators in a blinded manner. Relative (\%) and absolute ( $\mathrm{mm}$ ) FMD were calculated by determining peak post-occlusion vessel diameter relative to preocclusion diameter.

Biochemical Sampling and Analyses At each blood draw, $20 \mathrm{ml}$ of blood was collected from the antecubital vein via venipuncture into tubes containing either no preservative (Serum) or EDTA. Tubes were centrifuged at $3000 \mathrm{RPM}$ for $15 \mathrm{~min}$ at $4^{\circ} \mathrm{C}$. Serum/plasma was transferred into storage tubes and stored at $-80^{\circ} \mathrm{C}$ for future analysis.

As a measure of tissue disruption and recovery status, Creatine Kinase concentration was measured in duplicate using Diagnostics Chemicals Limited (Oxford, CT) reagents. Glucose (for confirmation of fasting) and Creactive protein (CRP) (a measure of local inflammation) were determined using a Cobas c 111 automated analyzer (Roche Diagnostics, Indianapolis, IN). Glucose and CRP reagents were purchased from Fisher Scientific. IL6 was determined using the Invitrogen Corporation (Carmarillo, CA) ultrasensitive ELISA. Cortisol was analyzed with the ALPCO Diagnostics (Salem, NH) ELISA to confirm abstinence from exercise and healthy population status. The Immunology Consultants Laboratory, Inc. (Newberg, OR) ELISA was used to determine alpha 1 -antichromotrypsin. All ELISAs were performed on the Molecular Devices VERSAmax tunable microplate 
reader. Both intra-assay and inter-assay variances were $<$ $5 \%$.

Physical Performance Testing Subjects performed a stationary standing test on a force platform (Advanced Mechanical Technology, Inc., Watertown, MA) to examine balance as determined by dispersion from center of pressure [37]. They were instructed to stand with feet together and arms relaxed and to the side for $40 \mathrm{sec}-$ onds. A countermovement vertical jump test was also performed on the force platform to determine muscle function and power capabilities [38]. Subjects initiated three maximal effort countermovement vertical jumps on a force plate (with their hands on their waists during the movement). In addition, subjects performed a maximal isometric handgrip strength test [39]. The hand grip was held by their side with their dominate hand. Subjects were asked to squeeze the handgrip instrument as hard and as quickly as possible for approximately 2-4 seconds with a two minute rest period between each repetition. Three trials were performed and the best score was recorded.

Perceptual Scales The Logbook utilized the National Institutes of Health PROMIS-57 Assessment Center scales for functioning [40], the Lequesne Knee Index [41] and the Knee Injury and Osteoarthritis Outcome Score (KOOS) [40,42]. We examined PROMIS-57 subscales of physical function, mood (anxiety), fatigue, and pain. The Lequesne index is a 10-question survey given to individuals with osteoarthritis of the knee accessing pain or discomfort, walking, and activities of daily living. The KOOS consists of 5 subscales: Pain, Symptoms, Function in Daily Living, Function in Sport and Recreation and Knee-Related Quality of life. Perceived energy was adapted from the Multidimensional Fatigue Symptom Inventory-Short Form (MFSI-SF)[43] and reported at the final visit of each cycle using a 5-point Likert scale.

Statistical Analyses The data are presented as means and standard deviations. Area under the curve calculations for blood markers using the trapezoidal method were also calculated for selected variables. Data were evaluated for assumptions for use of linear analysis models before analysis and then corrected with log10 transformations and reanalyzed when appropriate. A two-way analysis of variance was used to examine changes in the distribution. Where significant main effects were determined, an appropriate Tukey's or Fisher's LSD post hoc test were conducted to determine pairwise differences between treatments of sex. Intra-class correlation coefficients were all $R \geq 0.94$. The alpha level for significance in this investigatgion was be set at $\mathrm{P} \leq 0.05$.

\section{Results}

The supplement was well-tolerated by all subjects, both in terms of taste and absence of any side effects. No significant differences were shown between the pre- and post- placebo testing conditions for any variables. In addition, as applicable, no significant differences were seen between placebo and testing variables prior to supplementation.

Men displayed a significant decrease in IL-6 (from 1.2 \pm 0.2 to $0.7 \pm 0.4 \mathrm{pg} \cdot \mathrm{mL}^{-1}$ ) (Figure 2), Creatine Kinase (from $96 \pm 34$ to $67 \pm 23 \mathrm{IU} \cdot \mathrm{L}^{-1}$ ) (Table 2), and Alpha-1 Antichymotrypsin (from $108.9 \pm 38.6$ to $55.5 \pm 22.2$ ug. $\mathrm{mL}^{-1}$ ) (Figure 3), whereas women only showed a significant decrease in IL- 6 post supplementation (from $1.16 \pm 0.04$ to $\left.0.7 \pm 0.4 \mathrm{pg} \cdot \mathrm{mL}^{-1}\right)$. No differences were seen for cortisol, C- reactive protein, or brachial artery FMD (Table 2).

In terms of the perceptual variables, a significant increase in energy after supplementation was seen for both men (placebo: $1.8 \pm 0.7$; supplement: $3.7 \pm 0.8$ AUC) and women (placebo: $1.2 \pm 0.7$; supplement: $2.8 \pm$ 0.8 AUC) as shown in Table 3. Women also reported a lower anxiety level (from $53.0 \pm 8.9$ to $45.0 \pm 8.3$ AUC) that was not seen in men (remained at about $43.0 \pm 7.3$ AUC). Men showed a significant improvement in fatigue, pain, and joint pain after supplementation, which was not seen in women. No other significant differences were noted among the perceptual subscales.

The results of performance testing are seen in Table 4 . Men produced significantly higher power during the countermovement jump (from $2642 \pm 244$ to $3134 \pm$ $282 \mathrm{~W}$ ) and greater force in the grip strength test (from $42.1 \pm 5.9$ to $48.5 \pm 4.9 \mathrm{~kg}$ ) after supplementation. Women did not show improved power or strength, but did show a significant improvement in the postural sway test (from $0.52 \pm 0.13$ to $0.45 \pm 0.12 \mathrm{~cm}$ ).

\section{Discussion}

The primary finding of the current investigation is that a multi-nutrient supplement improved indices of inflammation and recovery in active, middle-age individuals. In addition to improved energy in both men and women, both sexes displayed sex-specific improvements in performance. This suggests that such a supplement may prolong functionality and physiological performance with age, thereby permitting individuals to continue to practice an active lifestyle.

\section{Decreased Inflammatory Status with IL-6}

There was a decrease in IL- 6 for both men and women as shown in Figure 2, indicating a decrease in inflammatory status. The normal cortisol, C-reactive protein levels, and brachial artery reactivity in our study indicated that our population consisted of otherwise healthy individuals unlikely to have localized inflammatory disorders. Whether through inhibition of IL-1 $\beta$ [29], NF$k B$ [32], or other factors, there may be an association 


\section{Interleukin6}

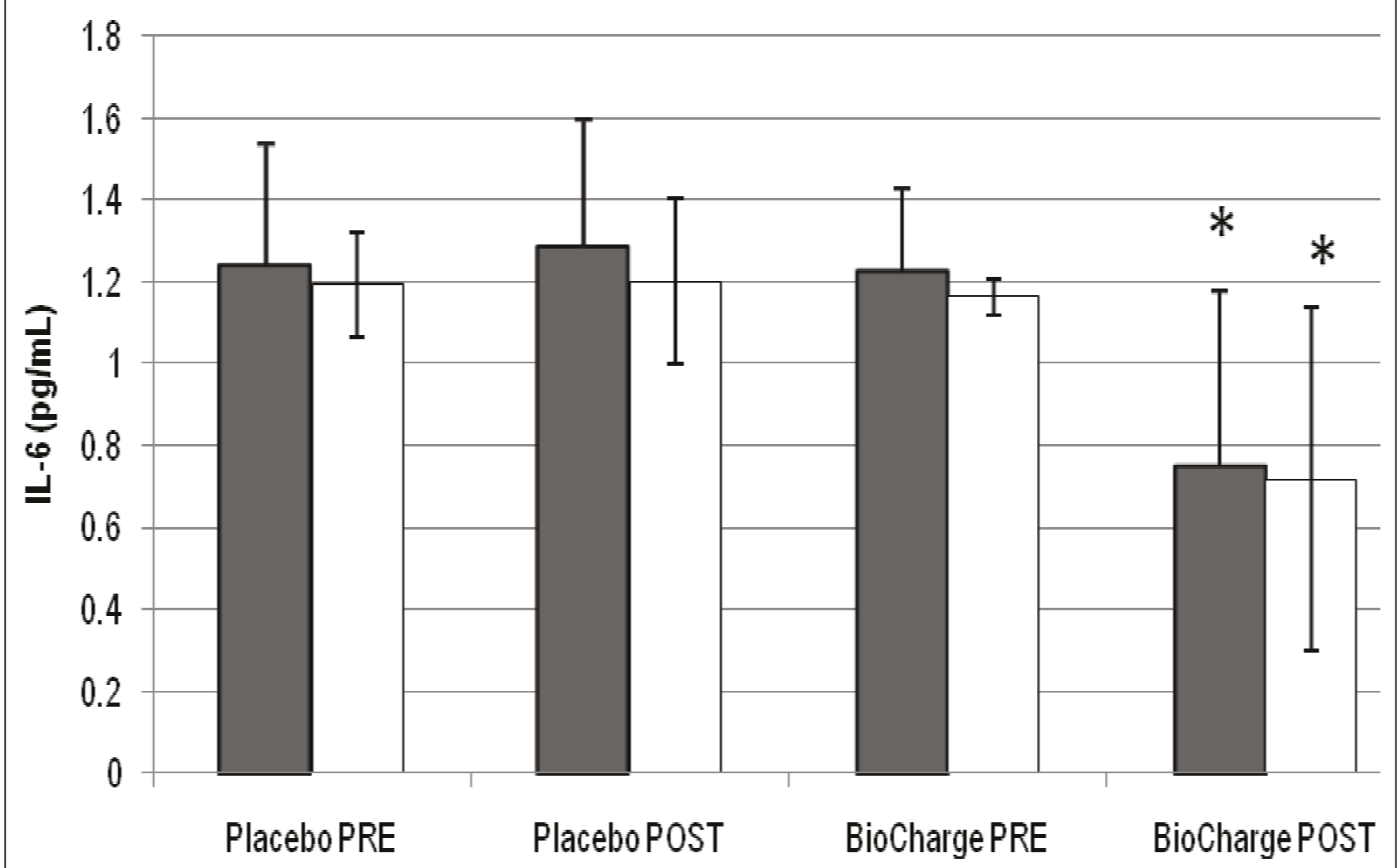

Figure 2 Interleukin-6 (IL-6). There was a significant decrease in interleukin-6 for both men and women from pre-supplementation, ${ }^{*}=$ P $\leq$ 0.05 from corresponding pre-BioCharge and placebo conditions. Grey: men; white: women.

between the plant extracts (cat's claw, green tea extract, quercetin, and taurine) and/or BCAA used in this investigation with the decrease in IL-6. Thus, even in an otherwise healthy population, the supplement effectively reduced inflammatory status in both men and women. While the subjects investigated did not display abnormal starting concentrations of IL-6, this may have important implications, as elevated IL-6 concentrations are associated with mortality, chronic disease, and other conditions [6]. Future research may help to clarify whether elevated normal IL-6 in healthy individuals is related to health outcomes in that population.

\section{Improved Physical Performance in Men}

As shown in Figure 3, alpha-1-antichymotrypsin (ACT) decreased in men but not women; in addition, vertical jump and grip strength also increased in men and not women. Given that men began the study with slightly higher ACT than women, this may suggest that the supplement permitted an increase in strength

Table 2 Physiological markers of inflammation in response to supplementation

\begin{tabular}{|c|c|c|c|c|c|c|c|c|}
\hline \multirow[b]{2}{*}{ Variables } & \multicolumn{4}{|c|}{ Men } & \multicolumn{4}{|c|}{ Women } \\
\hline & Pre Placebo & Post Placebo & Pre Suppl & Post Suppl & Pre Placebo & Post Placebo & Pre Suppl & Post Suppl \\
\hline & $M \pm S D$ & $M \pm S D$ & $M \pm S D$ & $M \pm S D$ & $M \pm S D$ & $M \pm S D$ & $M \pm S D$ & $M \pm S D$ \\
\hline Creatine Kinase (IU: $\left.\mathrm{L}^{-1}\right)$ & $92 \pm 25$ & $80 \pm 32$ & $96 \pm 34$ & $67 \pm 23^{*}$ & $68 \pm 42$ & $69 \pm 50$ & $66 \pm 32$ & $62 \pm 33$ \\
\hline Cortisol $\left(\mathrm{nmol} \cdot \mathrm{L}^{-1}\right)$ & $557 \pm 169$ & $613 \pm 128$ & $524 \pm 180$ & $515 \pm 187$ & $560 \pm 149$ & $513 \pm 129$ & $518 \pm 165$ & $541 \pm 148$ \\
\hline C-Reactive Protein $\left(\mathrm{mg} \cdot \mathrm{dL}^{-1}\right)$ & $0.22 \pm 0.25$ & $0.19 \pm 0.25$ & $0.17 \pm 0.24$ & $0.19 \pm 0.22$ & $0.10 \pm 0.10$ & $0.11 \pm 0.09$ & $0.1 \pm 0.1$ & $0.12 \pm 0.11$ \\
\hline Brachial Artery Reactivity (mm) & $4.6 \pm 0.7$ & $4.8 \pm 0.7$ & $4.7 \pm 0.8$ & $4.9 \pm 0.8$ & $3.7 \pm 0.6$ & $4.1 \pm 0.6$ & $3.8 \pm 0.5$ & $4.1 \pm 0.5$ \\
\hline
\end{tabular}

No significant differences were seen for placebo (either pre/post placebo or as compared to pre-supplementation). Pre Suppl = Pre-Supplementation testing; Post Suppl $=$ Post-Supplementation testing. ${ }^{*} p \leq 0.05$ as compared to supplementation pre-testing. 


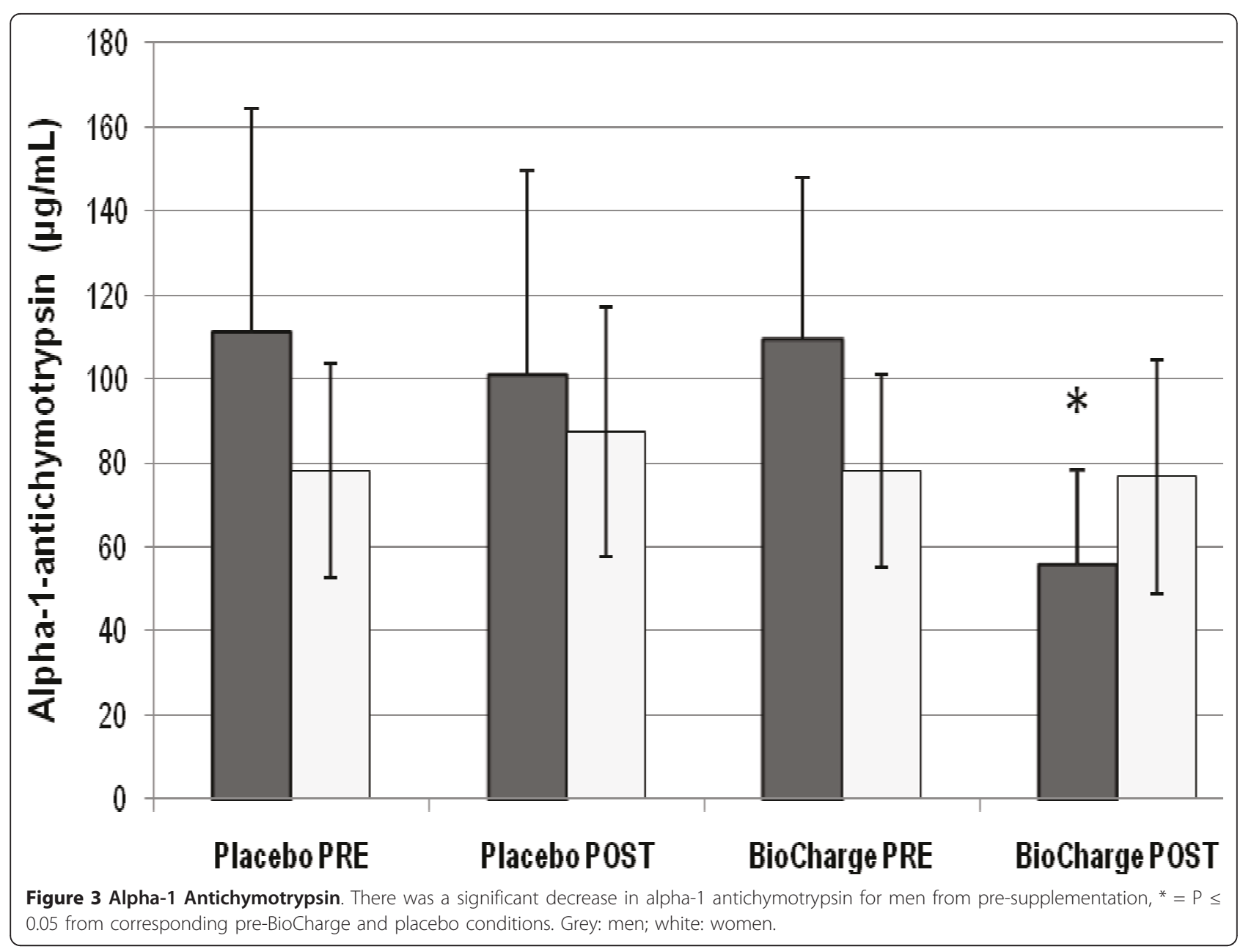

by reducing inflammation in those with higher levels of ACT.

Joint function may suggest another rationale for the improvement in strength and power performance in men. IL-6 status is associated with joint pain [44] but joint pain did not decrease in women despite a decrease in IL-6. On the other hand, it appears that alpha-1-antichymotrypsin (which did decrease in men but not women) can serve as a more sensitive marker to arthritis than measures such as C-Reactive Protein (which did not change in this investigation) [45]. Thus, whether through decreased inflammation or analgesic effects of BCAA, both overall pain and joint pain (which started slightly higher in men than in women) decreased in men but not in women. Thus the antiinflammatory nature of the supplement may have contributed to increased performance by reducing joint pain.

Table 3 Perceptual markers in response to supplementation (area under the curve)

\begin{tabular}{|c|c|c|c|c|c|c|c|c|}
\hline \multirow[b]{2}{*}{ Variables } & \multicolumn{4}{|c|}{ Men } & \multicolumn{4}{|c|}{ Women } \\
\hline & Pre Placebo & Post Placebo & Pre Suppl & Post Suppl & Pre Placebo & Post Placebo & Pre Suppl & Post Suppl \\
\hline & $M \pm S D$ & $M \pm S D$ & $M \pm S D$ & $M \pm S D$ & $M \pm S D$ & $M \pm S D$ & $M \pm S D$ & $M \pm S D$ \\
\hline Energy & - & $1.8 \pm 0.7 \wedge$ & - & $3.7 \pm 0.8^{*}$ & - & $1.2 \pm 0.7 \wedge$ & - & $2.8 \pm 0.8^{*}$ \\
\hline Anxiety & $43 \pm 6.3$ & $42 \pm 5.6$ & $43 \pm 7.2$ & $43 \pm 7.4$ & $50 \pm 6.5$ & $49 \pm 6.5$ & $53 \pm 8.9$ & $45 \pm 8.3^{*}$ \\
\hline Fatigue & $44.9 \pm 4.6$ & $43.7 \pm 4.5$ & $46.9 \pm 5$ & $35.8 \pm 6.7^{*}$ & $42.4 \pm 9$ & $43.3 \pm 5.3$ & $43 \pm 9.3$ & $43.2 \pm 9.5$ \\
\hline Joint Pain & $1.1 \pm 0.3$ & $1.1 \pm 0.3$ & $1.2 \pm 0.2$ & $0.5 \pm 0.3^{*}$ & $0.7 \pm 0.2$ & $0.8 \pm 0.1$ & $0.7 \pm 0.2$ & $0.7 \pm 0.2$ \\
\hline Pain Intensity & $0.8 \pm 0.06$ & $1.1 \pm 0.08$ & $1.1 \pm 0.09$ & $0.6 \pm 0.06^{*}$ & $0.8 \pm 0.07$ & $0.7 \pm 0.08$ & $0.6 \pm 0.06$ & $0.6 \pm 0.08$ \\
\hline
\end{tabular}

Please note (as applicable) that no differences were seen in placebo (either pre/post placebo or as compared to pre-supplementation). Pre Suppl = PreSupplementation testing; Post Suppl $=$ Post-Supplementation testing. ${ }^{*} p \leq 0.05$ as compared to supplementation pre-testing; $\wedge p<0.05$ as compared to placebo. 
Table 4 Performance responses to supplementation

\begin{tabular}{|c|c|c|c|c|c|c|c|c|}
\hline \multirow[b]{2}{*}{ Variables } & \multicolumn{4}{|c|}{ Men } & \multicolumn{4}{|c|}{ Women } \\
\hline & Pre Placebo & Post Placebo & Pre Suppl & Post Suppl & Pre Placebo & Post Placebo & Pre Suppl & Post Suppl \\
\hline & $M \pm S D$ & $M \pm S D$ & $M \pm S D$ & $M \pm S D$ & $M \pm S D$ & $M \pm S D$ & $M \pm S D$ & $M \pm S D$ \\
\hline Postural Sway $(\mathrm{cm})$ & $0.53 \pm 0.10$ & $0.48 \pm 0.13$ & $0.51 \pm 0.16$ & $0.56 \pm 0.22$ & $0.52 \pm 0.14$ & $0.52 \pm 0.12$ & $0.52 \pm 0.13$ & $0.45 \pm 0.12^{*}$ \\
\hline Vertical Jump (W) & $2697 \pm 212$ & $2761 \pm 322$ & $2642 \pm 244$ & $3134 \pm 282^{*}$ & $2006 \pm 244$ & $2046 \pm 282$ & $2077 \pm 229$ & $2039 \pm 409$ \\
\hline Grip Strength (kg) & $41.5 \pm 6.1$ & $41.8 \pm 6.2$ & $42.1 \pm 5.9$ & $48.5 \pm 4.9^{*}$ & $31.6 \pm 4.6$ & $33.3 \pm 4.5$ & $33 \pm 5.1$ & $33.3 \pm 5.5$ \\
\hline
\end{tabular}

No significant differences were seen in placebo (either pre/post placebo or as compared to pre-supplementation). Pre Suppl = Pre-Supplementation testing; Post Suppl $=$ Post-Supplementation testing. ${ }^{*} p \leq 0.05$ as compared to supplementation pre-testing

While strength increases may have been attributable to reductions in ACT, a decrease in Creatine Kinase (CK) was seen in men and was not seen in women. Once again, men began the investigation with higher CK. The reduced CK has been seen in investigations with taurine supplementation [46] and amino acid supplementation [47] but only to a limited degree with plant extracts such as green tea [48]. At the same time, amino acid supplementation has been shown to improve strength and power performance [49]. Thus, while the anti-inflammatory plant extracts appear to have played an important role in recovery, the amino acids may also have produced improved performance.

Finally, energy improved in both men and women, but fatigue only significantly decreased in men. The decrease in perceived fatigue may have resulted in improved performance. While the increased energy is likely due to the B Vitamins, other ingredients such as quercetin [50] cannot be excluded as contributors to this phenomenon. Thus, the supplementation protocol increased energy in both men and women, but the decrease in fatigue was only seen in men and may have influenced their improved performance on strength and power measures.

\section{Improved Physical Performance in Women}

In the present investigation, women (who have a higher risk of hip fracture than men) displayed improved medial-lateral balance with supplementation. At the same time, women also displayed a decrease in anxiety that was not seen in men (the anxiety level for women at baseline (50th percentile, normalized) was higher than men, but the anxiety level was similar after supplementation $\left(45^{\text {th }}\right.$ percentile for women, $43^{\text {rd }}$ for men)). Postural sway is strongly and linearly related to anxiety [51,52], suggesting that the decreased anxiety may have improved balance in women. Thus, whether through reduced anxiety or otherwise, the multi-nutrient supplementation improved balance in women and thereby reduced a risk factor for falling.

\section{Conclusions}

The purpose of the current investigation was to examine the effects of a multi-nutrient supplement on the recovery free-living, middle aged individuals from their active lifestyles in terms of physical performance, fatigue, mood, and other factors. As shown, men and women responded differentially and saw different benefits from the supplement. Inflammation, as determined by IL-6, clearly showed a benefit in both men and women. Both men and women reported increased energy and men displayed a decrease in perceptual fatigue. Anxiety decreased in women, which may have resulted in the decrease women showed in postural sway. Such an outcome could decrease the risk of hip fracture in women. Men showed a decrease in alpha-1antichymotrypsin, general and joint pain, and an improvement in physical performance. In all cases, the supplement helped to fight signs of aging and could act to prolong the ability of middle-aged individuals to continue their active lifestyles. It therefore appears that a multi-nutrient supplement is beneficial to recovery, inflammatory status, and performance of active men and women. Given the importance of physical activity itself in counteracting inflammation and other indices of aging, this supplement may promote a cycle of antiinflammatory activity and anti-aging benefits.

List of abbreviations

ACT: Alpha-1-antichymotrypsin; BCAA: Branched Chain Amino Acids; CK: Creatine Kinase; CVD: Cardiovascular Disease; FMD: Flow Mediated Dilation; IL-6: Interleukin-6; KOOS: Knee Injury and Osteoarthritis Outcome Score.

\section{Acknowledgements}

The authors would like to thank our subjects for their assistance and contributions to the research; Sarah Neuschwander for hours of data entry on this project and participation with data collection; Bill Haug for his endless dedication to recruitment and devotion to subjects; Kathy Les and Erin Burtner for their assistance with data collection; Paul Bloom for his contributions to the research; Dr. Anderson as our medical monitor; and our team of registered dieticians for their help in making this study possible. This investigation was funded by a grant from AdvoCare ${ }^{\mathrm{TM}} \mid$ nternational, Plano, TX.

\section{Authors' contributions}

All authors have reviewed the manuscript. CDN participated in design, coordinated the study and data collection, interpretation of results, drafting the manuscript. WJK a principal investigator, conceived of the study and its design, and drafting the manuscript. BRK carried out biochemical analyses, drafting the manuscript. NAK participated in the coordination of the investigation. BAC was principally responsible for ultrasound data collection and analysis. HYL participated in the interpretation of data and drafting of the manuscript. KDB contributed to 
design and data collection for ultrasound measures. BAC participated in the acquisition of the data and write up. TKS participated in the acquisition of the data and write up. DRH participated in the acquisition of the data and write up. CRD assisted in conception and analysis of study, drafting of write up. JSV-a principal investigator conceived of the study, participated in the design of the study and drafting manuscript write up.

\section{Competing interests}

Dr. William J. Kraemer is a member of the Advocare ${ }^{\mathbb{B}_{\oplus}}$ Sci-Med Board. This investigation was funded by AdvoCare ${ }^{T M}$ International, Plano, TX, USA and the company provided all of the supplement and placebos used in the study. There are no competing interests for the following authors: Courtenay Dunn-Lewis, Brian R Kupchak, Neil A Kelly, Brent A Creighton, Hui-Ying Luk, Kevin D Ballard, Brett A Comstock, Tunde K Szivak, David R Hooper, Craig R Denegar, Jeff S Volek

Received: 27 April 2011 Accepted: 7 September 2011 Published: 7 September 2011

Wu D, Meydani SN: Age-associated changes in immune and inflammatory responses: impact of vitamin E intervention. J Leukoc Biol 2008, 84(4):900-14.

2. Jankord R, Jemiolo B: Influence of physical activity on serum IL-6 and IL10 levels in healthy older men. Med Sci Sports Exerc 2004, 36(6):960-4.

3. Goldhammer $\mathrm{E}$, et al: Exercise training modulates cytokines activity in coronary heart disease patients. Int J Cardiol 2005, 100(1):93-9.

4. Reuben DB, et al: The associations between physical activity and inflammatory markers in high-functioning older persons: MacArthur Studies of Successful Aging. J Am Geriatr Soc 2003, 51(8):1125-30.

5. Hunt $\mathrm{KJ}$, et al: Inflammation in aging part 2: implications for the health of older people and recommendations for nursing practice. Biol Res Nurs 2010, 11(3):253-60.

6. Jensen GL: Inflammation: roles in aging and sarcopenia. JPEN J Parenter Enteral Nutr 2008, 32(6):656-9.

7. Handschin C, Spiegelman BM: The role of exercise and PGC1 alpha in inflammation and chronic disease. Nature 2008, 454(7203):463-9.

8. Peake J, Della Gatta P, Cameron-Smith D: Aging and its effects on inflammation in skeletal muscle at rest and following exercise-induced muscle injury. Am J Physiol Regul Integr Comp Physiol 2010, 298(6): R1485-95.

9. Fonseca JE, et al: Interleukin-6 as a key player in systemic inflammation and joint destruction. Autoimmun Rev 2009, 8(7):538-42.

10. Madhok $R$, et al: Serum interleukin 6 levels in rheumatoid arthritis: correlations with clinical and laboratory indices of disease activity. Ann Rheum Dis 1993, 52(3):232-4.

11. Pawlik $A$, et al: Interleukin-10 promoter polymorphism in patients with rheumatoid arthritis. Clin Rheumatol 2005, 24(5):480-4.

12. Daynes RA, et al: Altered regulation of IL-6 production with normal aging. Possible linkage to the age-associated decline in dehydroepiandrosterone and its sulfated derivative. J Immunol 1993, 150(12):5219-30

13. Schaap LA, et al: Inflammatory markers and loss of muscle mass (sarcopenia) and strength. Am J Med 2006, 119(6):526 e9-17.

14. Guideline for the prevention of falls in older persons. American Geriatrics Society, British Geriatrics Society, and American Academy of Orthopaedic Surgeons Panel on Falls Prevention. J Am Geriatr Soc 2001, 49(5):664-72.

15. Trombetti A, et al: Survival and potential years of life lost after hip fracture in men and age-matched women. Osteoporos Int 2002, 13(9):731-7.

16. Donato AJ, et al: Vascular endothelial dysfunction with aging: endothelin-1 and endothelial nitric oxide synthase. Am J Physiol Heart Circ Physiol 2009, 297(1):H425-32.

17. Celermajer DS, et al: Endothelium-dependent dilation in the systemic arteries of asymptomatic subjects relates to coronary risk factors and their interaction. J Am Coll Cardiol 1994, 24(6):1468-74.

18. Widlansky ME, et al: The clinical implications of endothelial dysfunction. J Am Coll Cardiol 2003, 42(7):1149-60.

19. Vita JA, et al: Brachial artery vasodilator function and systemic inflammation in the Framingham Offspring Study. Circulation 2004, 110(23):3604-9.
20. Pierce $G L$, et al: Nuclear factor-\{kappa\}B activation contributes to vascular endothelial dysfunction via oxidative stress in overweight/obese middleaged and older humans. Circulation 2009, 119(9):1284-92.

21. Joseph JA, et al: Oxidative stress and inflammation in brain aging: nutritional considerations. Neurochem Res 2005, 30(6-7):927-35.

22. Matsumoto K, et al: Branched-chain amino acid supplementation attenuates muscle soreness, muscle damage and inflammation during an intensive training program. J Sports Med Phys Fitness 2009, 49(4):424-31.

23. Buse MG, Reid SS: Leucine. A possible regulator of protein turnover in muscle. J Clin Invest 1975, 56(5):1250-61.

24. De Bandt JP, Cynober L: Therapeutic use of branched-chain amino acids in burn, trauma, and sepsis. J Nutr 2006, 136(1 Suppl):308S-13S.

25. Schuller-Levis GB, Park E: Taurine: new implications for an old amino acid. FEMS Microbiol Lett 2003, 226(2):195-202.

26. Mandel $S$, et al: Cell signaling pathways in the neuroprotective actions of the green tea polyphenol (-)-epigallocatechin-3-gallate: implications for neurodegenerative diseases. J Neurochem 2004, 88(6):1555-69.

27. Cabrera C, Artacho R, Gimenez R: Beneficial effects of green tea-a review. J Am Coll Nutr 2006, 25(2):79-99.

28. Schneider C, Segre T: Green tea: potential health benefits. Am Fam Physician 2009, 79(7):591-4.

29. Comalada $M$, et al: In vivo quercitrin anti-inflammatory effect involves release of quercetin, which inhibits inflammation through downregulation of the NF-kappaB pathway. Eur J Immunol 2005, 35(2):584-92.

30. Kandere-Grzybowska K, et al: Regulation of IL-1-induced selective IL-6 release from human mast cells and inhibition by quercetin. $\mathrm{Br} J$ Pharmacol 2006, 148(2):208-15.

31. Davis JM, Murphy EA, Carmichael MD: Effects of the dietary flavonoid quercetin upon performance and health. Curr Sports Med Rep 2009, 8(4):206-13.

32. Aguilar $\mathrm{JL}$, et al: Anti-inflammatory activity of two different extracts of Uncaria tomentosa (Rubiaceae). J Ethnopharmacol 2002, 81(2):271-6.

33. Skarupski KA, et al: Longitudinal association of vitamin B-6, folate, and vitamin B-12 with depressive symptoms among older adults over time. Am J Clin Nutr 2010, 92(2):330-5.

34. Kennedy DO, et al: Effects of high-dose B vitamin complex with vitamin $C$ and minerals on subjective mood and performance in healthy males. Psychopharmacology (Berl) 2010, 211(1):55-68.

35. Ballard KD, et al: Acute ingestion of a novel whey-derived peptide improves vascular endothelial responses in healthy individuals: a randomized, placebo controlled trial. Nutr J 2009, 8:34.

36. Doshi SN, et al: Flow-mediated dilatation following wrist and upper arm occlusion in humans: the contribution of nitric oxide. Clin Sci (Lond) 2001, 101(6):629-35.

37. Holviala $\mathrm{JH}$, et al: Effects of strength training on muscle strength characteristics, functional capabilities, and balance in middle-aged and older women. J Strength Cond Res 2006, 20(2):336-44.

38. Dixon $P G$, et al: The impact of cold-water immersion on power production in the vertical jump and the benefits of a dynamic exercise warm-up. J Strength Cond Res 2010, 24(12):3313-7.

39. Ho JY, et al: I-Carnitine I-tartrate supplementation favorably affects biochemical markers of recovery from physical exertion in middle-aged men and women. Metabolism 2010, 59(8):1190-9.

40. Cella D, et al: The Patient-Reported Outcomes Measurement Information System (PROMIS) developed and tested its first wave of adult selfreported health outcome item banks: 2005-2008. J Clin Epidemiol 2010, 63(11):1179-94.

41. Lequesne MG, et al: Indexes of severity for osteoarthritis of the hip and knee. Validation-value in comparison with other assessment tests. Scand J Rheumatol Suppl 1987, 65:85-9.

42. Roos EM, Toksvig-Larsen S: Knee injury and Osteoarthritis Outcome Score (KOOS) - validation and comparison to the WOMAC in total knee replacement. Health Qual Life Outcomes 2003, 1:17.

43. Stein $\mathrm{KD}$, et al: Further validation of the multidimensional fatigue symptom inventory-short form. J Pain Symptom Manage 2004, 27(1):14-23.

44. Schaible $\mathrm{HG}$, et al: The role of proinflammatory cytokines in the generation and maintenance of joint pain. Ann N Y Acad Sci 2010, 1193:60-9.

45. Hrycaj PZ: Systemic inflammation in osteoarthritis. Ann Rheum Dis 2004, 63(6):750-1, author reply 751 . 
46. Silva $L A$, et al: Taurine supplementation decreases oxidative stress in skeletal muscle after eccentric exercise. Cell Biochem Funct 2011, 29(1):43-9.

47. Sharp CP, Pearson DR: Amino acid supplements and recovery from highintensity resistance training. J Strength Cond Res 2010, 24(4):1125-30.

48. Eichenberger P, Colombani PC, Mettler S: Effects of 3-week consumption of green tea extracts on whole-body metabolism during cycling exercise in endurance-trained men. Int J Vitam Nutr Res 2009, 79(1):24-33.

49. Kraemer WJ, et al: Effects of amino acids supplement on physiological adaptations to resistance training. Med Sci Sports Exerc 2009, 41(5):1111-21.

50. Olson CA, et al: Effects of 2 adenosine antagonists, quercetin and caffeine, on vigilance and mood. J Clin Psychopharmacol 2010, 30(5):573-8

51. Wada M, Sunaga N, Nagai M: Anxiety affects the postural sway of the antero-posterior axis in college students. Neurosci Lett 2001, 302(23):157-9.

52. Redfern MS, Furman JM, Jacob RG: Visually induced postural sway in anxiety disorders. J Anxiety Disord 2007, 21(5):704-16.

doi:10.1186/1475-2891-10-90

Cite this article as: Dunn-Lewis et al:: A multi-nutrient supplement reduced markers of inflammation and improved physical performance in active individuals of middle to older age: a randomized, double-blind, placebo-controlled study. Nutrition Journal 2011 10:90.

\section{Submit your next manuscript to BioMed Central} and take full advantage of:

- Convenient online submission

- Thorough peer review

- No space constraints or color figure charges

- Immediate publication on acceptance

- Inclusion in PubMed, CAS, Scopus and Google Scholar

- Research which is freely available for redistribution

Submit your manuscript at www.biomedcentral.com/submit 